\title{
AUTO-IGNITION PERFORMANCE OF AN ELECTRIFIED MICROREACTOR WITH CONSTRUCTAL GEOMETRIES
}

\author{
Ademola Adebukola Dare $^{1}$ - Ebenezer Olubunmi Ige ${ }^{2 *}-$ Olukunle Cornelius Akinpelu $^{1}$
}

${ }^{1}$ Department of Mechanical Engineering, University of Ibadan, Ibadan - 200284 Nigeria

${ }^{2}$ Department of Mechanical and Mechatronic Engineering, Afe Babalola University, Ado-Ekiti - 360231 Nigeria

\begin{tabular}{l} 
ARTICLE INFO \\
\hline Article history: \\
Received: 28. 3. 2018. \\
Received in revised form: 11. 2. 2019. \\
Accepted: 20. 2. 2019. \\
\hline Keywords: \\
Shape factor \\
Constructal parameter \\
Combustion \\
Microchannel \\
Electric field \\
\hline DOI: http://doi.org/10.30765/er.40.2.06
\end{tabular}

\section{Introduction}

Over the past two decades, huge advancements that leverage on Micro-Electro-Mechanical Systems (MEMS) have shifted the concern of many towards

\begin{abstract}
:
Common techniques employed to minimize ignition energy of gaseous fuels in micro reactors such as the use of catalyst are being plagued with setbacks. This report demonstrates the use of electric field to sustain combustion, minimize heat loss and enhance reactant mixing in microchannels of varying geometries. We set two defining constructal parameters for serpentine and straight microchannels of 0.05 to 0.25 to investigate geometric effect on the mixing of the reactants. Inlet concentration of propane and oxygen was set at $0.15 \mathrm{~mol} / \mathrm{dm}^{3}$ and $0.7 \mathrm{~mol} / \mathrm{dm}^{3}$ respectively. Reynolds numbers 400, 470, 530, 600 and 670 corresponding to inlet velocities of $0.06 \mathrm{~m} / \mathrm{s}$, $0.07 \mathrm{~m} / \mathrm{s}, 0.08 \mathrm{~m} / \mathrm{s}, 0.09 \mathrm{~m} / \mathrm{s}$ and $0.1 \mathrm{~m} / \mathrm{s}$ were used in the straight channel to study the dependence of reaction rate, temperature drop and reactants diffusion on the combustion process. We report that at an inlet temperature of $500 \mathrm{~K}$ which was below the propane's auto ignition temperature of $743 \mathrm{~K}$, the reaction could occur in the presence of a $50 \mathrm{~V}$ applied voltage. Increasing constructual parameter $(\beta)$ yielded an increase in reaction rate and a decrease in temperature drop. At the same constructual parameter, the serpentine geometry displayed a better result with the peak reaction rate of $894 \mathrm{~mol} / \mathrm{m}^{3} \mathrm{~s}$. More so, increase in the Reynolds number and shape factor for the two geometries led to an increase in reaction rate and propane consumption. These findings could be suitably beneficial to provide minimal fuel requirement for miniaturized vehicles and micro-heat engines.
\end{abstract}

energy utilization to meet small but high energy density requirement of micro machines. Microcombustors have been described as a potential solution [1]. Oxidation of hydrocarbon in minutesized reactors have energy density in the order being

\footnotetext{
* Corresponding author. Tel.: +234-803-4296-362

E-mail address: ige.bababunmi@gmail.com
} 
two higher than the convectional lithium-ion batteries [2], [3]. Multiplexing the capabilities of micro reactors with appropriate energy conversion could result into a credible and reliable alternative for microscale devices. However, there are challenges that limit the utilization of the micro reactors. Thermal losses in the confinements of micro combustion is one of these limiting issues; this is associated with down scaling. When devices' dimensions are scaled down, their surface area to volume ratio becomes larger, resulting in larger heat loss rate (which scales with the surface area) relative to heat generation rate (which scales with the volume), which causes flame quenching for power generation [4]. To overcome this difficulty and establish stable heat generation in micro-scale combustors, thermal management, several efforts have being reported and numerous on-going endeavours on this subject.

Fundamentally, the catalysts are ubiquitous in the reaction processes. In the micro scale reaction systems, catalytic combustion offers huge possibilities because the rate of transport of reacting species and surface area for catalysis increases proportionally as the size decreases. This could result into increased rate of reaction, stability of combustion processes and intensification of thermal energy at minimized ignition energy [5]. Hence, sustaining catalytic oxidation at temperatures below gas-phase combustion could minimize thermal stress and reduce heat loss [6]. A serious attempt to utilize catalyst supported combustion in micro reactors has been reported [7] and highlighted approaches based on packed, monolithic and wallcoated were implemented for the catalytic process in micro-combustors [8]. Platinum and Rhodium was utilized to catalyze oxidation of propane-butane mixture in a slit micro reactor to achieve methane production. The report demonstrated high catalytic activity favoured the oxidation of gaseous fuels at low combustion temperature and reduced process time. [9] reported catalysis aided combustion of propane under several physicochemical conditions. The experiment achieved the reaction temperature of 3250C and at a space velocity of 300NL/(hgcat), full propane conversion over $\mathrm{Pt} / \mathrm{MoOx} / \mathrm{Al} 2 \mathrm{O} 3$ catalyst in the slight excess of oxygen. Pt catalyst promoted by MoOx and WOx showed to be stable for over $1,000 \mathrm{~h}$ without any detectable degradation in performance for low and high temperature applications respectively. [10] $\mathrm{Pd} / \mathrm{NiCrO} 4$ catalyst was utilized to achieve complete combustion of methane and hydrogen in a conduit at reduced ignition temperature. [11] showed that the catalysis of propane fuel in platinum coated microchannel investigated blowout limits under varying pressure conditions. Platinum nanoparticles were explored to catalyze multiple fuels of hydrocarbon fuels such as propane, butane and methane in an attempt to study the behaviour of reactants under the catalysis sustained combustion processes [12]. [13] presented numerical modelling of the chemical process of combustion based on Arrhenius assumptions, gas flow based on the Navier-Stokes equation and the Maxwell-Stefan equation was used to capture the concentration and temperature dependence of various species diffusivities. The temperature profile from the simulation ranged from $850-860 \mathrm{~K}$ and the propane concentration fell from $0.150 \mathrm{~mol} / \mathrm{m}^{3}$ to $0.100 \mathrm{~mol} / \mathrm{m}^{3}$. In [14] a numerical modelling was performed to delineate the dynamics of flow and reaction in catalytically enhanced methane-air micro reactor. Other numerical studies from this group on thermal transport in microchannels have been reported on gravity effect on thermal distribution in 2D microchannel [15], 3D microchannel [16] and variable dimensions of plain slab using vortex element techniques [17]. The study highlighted the critical role of velocity equalization for flow and reaction to achieve stability in these two competing processes.

Meso-scale combustion systems are built on the premise that convenience energy conversion process and improved output power is achievable at micron scale. However, this procedure is favoured by a multiple chamber arrangement or parallelization of micro-combustion channels. Recently, Zou et al., 2018 designed the first four-chamber meso-scale combustion chambers where numerical investigation was performed using hydrogen fuel [18]. The study reported a specified stoichiometric parameter required to achieve purely counter flow at uniform wall temperature for a given thermal conductivity of the chamber. In a similar study, the effects of porous wall on thermal performance of hydrogen fuel in micro combustion chamber were investigated to determine its application for energy conversion in thermo photovoltaic systems [19]. To improve flame stability and energy conversion efficiency, the need to consider varying in geometric features of micro combustion channels was considered. Peng and co-workers reported the impact of calculated changes based on a construtal parameter of frontal cavity could support the efficiency of total energy conversion in a micro thermophotovoltaic (TPV) system [20]. Earlier, Zuo and et al. had showed that 
variation of velocity, temperature and specific fields in micro-combustion systems could yield high performance for energy storage and conversion [21]. From this reports, it can be seen that variation in the geometric parameters as well the thermophysical properties and process conditions could yield an improvement in energy conversion in a micro combustion system.

Channel clogging at micron-sized length scale is the big challenge confronting the utilization of a catalyst to enhance thermal transport and sustain combustion in micro reactors. The introduction of solid phase substance causes the formation of particulate solids along the regime of gaseous fuels in an elevated temperature condition [22]. These particles settle at the wall or the minute size reactor, thus reducing the hydraulic diameter for combustion and constituting additional resistance to thermal transport. The resultant of clogging is usually resulting into increase in ignition energy and possesses the likelihood of flame quenching. Since clogging is often regarded as micro-specific fouling, several works are on-going in the attempt to combat clogging in micro reactors for example, the use of a catalyst may improve energy conversion efficiency in microreactors at very short residence time [23]; imposition of geometric features to prevent gas clogging was investigated [24]; Pribyl and coworkers showed that electric field could be explored to control precipitation which would in turn delay clog formation in micro combustion capillaries [25]. Other techniques for combating clogging in micro reactors are explicitly presented in the works of Schoenitz and company [26]. This paper reports the intervention of electric field in the minimizing autoignition energy and sustenance of oxidation processes for gaseous fuels in micrometer-sized confinements. Using the established mathematical formulation, the present investigate delineate important mechanics on electric field facilitated multiphase processes which may provide the needed enhancement of combustion below auto-ignition temperature in micro heat engines.

\section{Methodology}

A single phase flow simply means a flow in which the participating species have one phase and not a combination of any two or more phases. For example, this work uses reactants and products in the gaseous phase. The combustion equation below describes further

$$
\begin{gathered}
C_{n} H_{2 n+2_{(g)}}+\frac{3 n+1}{2} \mathrm{O}_{2_{(g)}} \underset{\text { catalyst }}{\stackrel{\text { Electric field }}{\rightarrow}} \\
n \mathrm{CO}_{2_{(g)}}+(n+1) \mathrm{H}_{2} \mathrm{O}_{(g)}
\end{gathered}
$$

The subscript (g) denotes that the specie is in the gaseous state. This work will use electric field in place of a catalyst and the effect will be measured across the reactor geometries.

The following assumptions were made: the flow is steady; the flow is a single phase flow; the gases obey ideal gas laws; the flow is incompressible, i.e. density is constant throughout the channel; the flow is laminar with Reynolds number less than 2000; no slip condition was assumed at the walls; 2-D flow equations are used; mobility in electric field; species are taken to be diluted in a solvent; no diffusion across the boundaries.

\subsection{Channel geometry}

Two channel geometries would be used in carrying out the simulation- straight channel and serpentine channel, and a constructal parameter $\beta_{1}$ and $\beta_{2}$ will be used for the straight and serpentine channels respectively. It is defined below as:

$$
\beta_{1}=\frac{W_{c h}}{L_{c h}} ; \beta_{2}=\frac{t}{L_{c h}}
$$

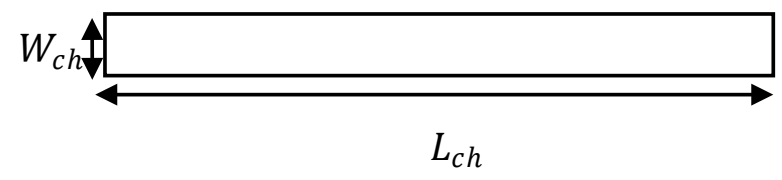

Figure 1. Configurations of the straight channel reactor

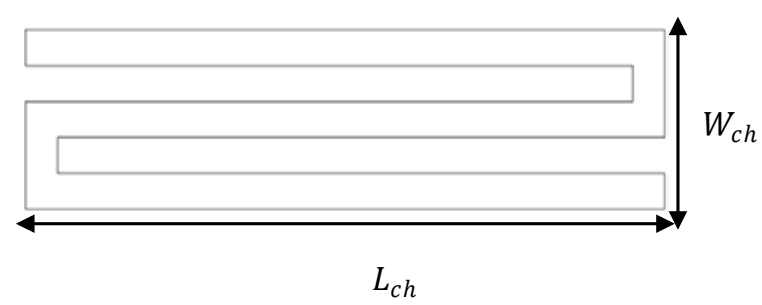

Figure 2. Configurations of the serpentine channel reactor 


\subsection{Governing Equations}

The flow field, temperature field, concentration field and electric field would be modelled mathematically using the basic equations presented below.

\section{Continuity equation:}

$$
\frac{\partial u}{\partial x}+\frac{\partial v}{\partial y}=0
$$

$u=$ component of velocity in $x$-direction ;

$v=$ component of velocity in $y$-direction

Using the following dimensionless parameters;

$$
u^{*}=\frac{u}{\bar{u}}, v^{*}=\frac{v}{\bar{u}}, x^{*}=\frac{x}{D_{h}}, y^{*}=\frac{y}{D_{h}}
$$

Then, (3) becomes

$$
\frac{\partial u^{*}}{\partial x^{*}}+\frac{\partial v^{*}}{\partial y^{*}}=0
$$

\section{Momentum equation:}

$$
\begin{aligned}
& u \frac{\partial u}{\partial x}+v \frac{\partial u}{\partial x}= \\
& -\frac{1}{\rho} \frac{\partial \mathrm{P}}{\partial \mathrm{x}}+\frac{\mu}{\rho}\left(\frac{\partial^{2} u}{\partial x^{2}}+\frac{\partial^{2} v}{\partial y^{2}}\right)+F
\end{aligned}
$$

where $P=$ pressure, $F=\rho_{e} E$,

$E$ = electric field strength;

$\rho_{e}=$ charge density $E=-\frac{\partial \mathrm{V}}{\partial \mathrm{x}}$

$V=$ applied potential

Defining the dimensionless parameters as:

$$
\begin{gathered}
P^{*}=\frac{P}{\rho u^{2}} ; R_{e}=\frac{\rho u D_{h}}{\mu} ; u^{*}=\frac{u}{\bar{u}} \\
v^{*}=\frac{v}{\bar{u}} ; x^{*}=\frac{x}{D_{h}}, y^{*}=\frac{y}{D_{h}}
\end{gathered}
$$

$$
\begin{aligned}
& u^{*} \frac{\partial u^{*}}{\partial x^{*}}+v^{*} \frac{\partial u^{*}}{\partial y^{*}}= \\
& -\frac{\partial P^{*}}{\partial x^{*}}+\frac{1}{R_{e}}\left(\frac{\partial^{2} u^{*}}{\partial x^{* 2}}+\frac{\partial^{2} v^{*}}{\partial y^{* 2}}\right)-F^{*}
\end{aligned}
$$

$$
F^{*}=-\frac{\rho_{e} k_{b} T}{\overline{u^{2}} z e} \frac{\partial \mathrm{V}^{*}}{\partial \mathrm{x}^{*}}
$$

Boundary conditions to be used for the flow modelling are given as: no slip boundary condition at the wall i.e. $u=0$ at channel wall. Normal in flow velocity at the inlet i.e. $u=U_{i n}$. normal flow condition at outlet i.e.

$n^{T}\left[-p \mathrm{I}+\mu\left(\nabla u+(\nabla u)^{T}\right)\right] n=-p_{0}$.

Volume force to characterize for the body force $F=\rho_{e} E$.

\section{Energy equation:}

$$
\rho c_{p} u . \nabla T=\nabla \cdot(k \nabla T)+Q
$$

where

$c_{p}=$ specific heat capacity,

$k=$ thermal conductivity,

$T=$ temperature,

$\rho=$ density,

$u=$ velocity,

$Q=$ heat source.

Assuming constant k, Eq. (10) can be rewritten as: $\rho c_{p} u . \nabla T=k . \nabla^{2} T+Q$,

$$
u . \nabla T=\alpha . \nabla^{2} T+Q
$$

where $\alpha$ is a thermal diffusivity given by: $\alpha=\frac{k}{\rho c_{p}}$ Using the following dimensionless parameters:

$$
\begin{gathered}
T^{*}=\frac{T-T_{s}}{T_{i}-T_{s}} ;\left(\nabla^{*}\right)^{2}=\frac{\nabla^{2}}{1 / D_{h}{ }^{2}} ; \\
\nabla^{*}=\frac{\nabla}{1 / D_{h}} ; u^{*}=\frac{u}{\bar{u}}
\end{gathered}
$$


Eq. (12) becomes:

$$
u^{*} \nabla^{*} T^{*}=\frac{\left(\nabla^{*}\right)^{2} T^{*}}{P_{e}}
$$

where $P_{e}$ is the Pecklet number $=\frac{\bar{u} D_{h}}{\alpha}$

Boundary conditions to be used:

- no thermal insulation, i.e. the boundaries interact with the environment

- inlet temperature will be specified as $T_{i}$

- outflow at the exit i.e. $-n .(k \nabla T)=0$

- radiation at the external walls i.e. $-n .(k \nabla T)=\varepsilon_{\sigma}\left(T_{s}^{4}-T^{4}\right)$

- heat source will be specified from the heat of chemical reaction.

\section{Diffusion equation:}

A convective-dispersive model [27] describes migration of gaseous fuel under the imposition of external electric field, and the steady flow assumption, the Fick's law can be modified as follows;

$$
\nabla .\left(-\mathrm{D}_{i} \nabla c_{i}-z_{i} u_{m, j} \Gamma c_{i} \nabla V\right)+\mathrm{u} . \nabla c_{i}=R_{i}
$$

where $\Gamma_{i}$ is the flux of the diffusing material;

$V=$ Applied potential,

$D_{i}=$ diffusion coefficient of specie,

$c_{i}=$ concentration of specie,

$z_{i}=$ charge number of specie,

$R_{i}=$ rate of reaction of specie,

$u_{m, j}$ defined as $\frac{D_{i}}{R T}$ is known as the mobility,

$u=$ velocity component.

The following boundary conditions are used for the transport property

- no flux at the boundaries except inlet and outlet. This implies that $-n \cdot N_{i}=0$ where $N_{i}=-D_{i} \nabla c_{i}+w c_{i}$,

- inflow condition at inlet where initial concentration of diffusing species are specified.
${ } \mathrm{C}_{3} \mathrm{H}_{8}$ (propane concentration $)=$

$0.15\left[\mathrm{~mol} / \mathrm{dm}^{3}\right]$

and

$\mathrm{CO}_{2}$ (oxygen concentration $)=$

$0.70\left[\mathrm{~mol} / \mathrm{dm}^{3}\right]$

while the initial concentrations of steam $\left(\mathrm{CH}_{2} \mathrm{O}\right)$ and carbon dioxide $\left(c \mathrm{CO}_{2}\right)$ are specified as zero $(0)$.

- outflow condition at the outlet i.e. - n. $-D_{i} \nabla c_{i}=0$

\section{Combustion equation:}

Using propane as the fuel for this work, the following chemical equation holds:

$$
\mathrm{C}_{3} \mathrm{H}_{8}+5 \mathrm{O}_{2} \underset{\text { Electric Field }}{\rightarrow} 3 \mathrm{CO}_{2}+4 \mathrm{H}_{2} \mathrm{O}
$$

\section{Arrhenius equation:}

$$
k_{\text {rate }}=A e^{\frac{-E_{a}}{R_{g} T}}
$$

$A$ is pre exponential factor, $E_{a}$ is activation energy, $R$ is universal gas constant, $T$ is temperature, $R=k_{\text {rate }}\left[C_{3} H_{8} \mathrm{O}_{2}\right] ; R=$ rate of reaction.

\section{Electric field:}

The electric field distribution in microchannel is described using a combination of Poisson-Boltzman with reference to zeta potential and Debye-Huckel parameter.

\section{Poisson-Boltzmann equation:}

$$
\frac{\partial^{2} \Psi}{\partial \mathrm{x}^{2}}+\frac{\partial^{2} \Psi}{\partial \mathrm{y}^{2}}=-\frac{\rho_{e}}{\varepsilon_{0} \varepsilon_{r}}
$$

where: $\Psi$ = electrical potential,

$\varepsilon_{0}=$ permittivity of vacuum and

$\varepsilon_{r}=$ dielectric constant of medium,

$\varepsilon=\varepsilon_{0} \varepsilon_{r}=$ permittivity of material, 
$\rho_{e}=\left(n^{+}-n^{-}\right) z e=-2 n_{0} z e \sinh \left(\frac{z e \Psi}{k_{b} T}\right)$,

$\rho_{e}=$ charge density,

$e=$ proton charge,

$z=$ charge number, $\rho_{e}=\varepsilon \nabla . E$,

$E=$ electric field strength,

$n_{0}=$ bulk ionic concentrations,

$z=$ ionic valence,

$k_{b}=$ Boltzmann constant.

The following dimensionless properties would be used in transforming the equation 20-21 above

$$
\begin{gathered}
x^{*}=\frac{x}{D_{h}} ; y^{*}=\frac{y}{D_{h}} ; \Psi^{*}=\frac{z e \Psi}{k_{b} T} \\
\frac{\partial^{2} \Psi^{*}}{\partial x^{* 2}}+\frac{\partial^{2} \Psi^{*}}{\partial y^{* 2}}=\frac{2 n_{0} z^{2} e^{2}}{\varepsilon k_{b} T} D_{h}{ }^{2} \sinh \left(\Psi^{*}\right)
\end{gathered}
$$

Debye-Huckel parameter $\left(\lambda^{2}\right)$ :

$$
\begin{gathered}
\left(\lambda^{2}\right)=\frac{2 n_{0} z^{2} e^{2}}{\varepsilon k_{b} T} \\
\frac{\partial^{2} \Psi^{*}}{\partial x^{* 2}}+\frac{\partial^{2} \Psi^{*}}{\partial y^{* 2}}=k^{2} D_{h}{ }^{2} \sinh \left(\Psi^{*}\right)
\end{gathered}
$$

The following boundary conditions would be employed in solving the equation 21 above.

when $x^{*}=0, \frac{\partial \Psi^{*}}{\partial x^{*}}=0 ; x^{*}=\frac{W_{c h}}{D_{h}}$,

$\Psi^{*}=\frac{z e \zeta}{k_{b} T}$,

where $\zeta=$ zeta potential and

$W_{c h}=$ channel width $y^{*}=0, \frac{\partial \psi^{*}}{\partial y^{*}}=0, x^{*}=\frac{H_{c h}}{D_{h}}$,

$\Psi^{*}=\frac{z e \zeta}{k_{b} T}$,

$H_{c h}=$ channel height,

$\frac{1}{\lambda}=$ EDL thickness.

Table 1. Geometry effect on combustion process

\begin{tabular}{|l|c|c|c|c|}
\hline \multirow{2}{*}{$\begin{array}{l}\text { Shape } \\
\text { parameter }(\beta)\end{array}$} & \multicolumn{3}{|c|}{ Geometry } \\
\cline { 2 - 5 } & $\begin{array}{c}\text { Temperature drop } \\
(\mathrm{K})\end{array}$ & $\begin{array}{c}\text { Reaction rate } \\
\left(\mathrm{mol} / \mathrm{m}^{3} \mathrm{~s}\right)\end{array}$ & $\begin{array}{c}\text { Temperature drop } \\
(\mathrm{K})\end{array}$ & $\begin{array}{c}\text { Reaction rate } \\
\left(\mathrm{mol}^{3} \mathrm{~m}^{3} \mathrm{~s}\right)\end{array}$ \\
\hline 0.05 & $500-431$ & 46.2 & $500-420$ & 81.1 \\
\hline 0.10 & $500-459$ & 95.4 & $500-447$ & 138 \\
\hline 0.15 & $500-470$ & 187 & $500-458$ & 286 \\
\hline 0.20 & $500-476$ & 326 & $500-459$ & 544 \\
\hline 0.25 & $500-479$ & 492 & $500-459$ & 894 \\
\hline
\end{tabular}

\section{Results}

The mathematical expressions for velocity, concentration and electric fields and reaction specific models were computed over the geometries prescribed above using on Finite Element Method (FEM) scheme on the platform of COMSOL Multiphysics. Grid dependence study showed no significance variation in the outcome of our study.

\subsection{Electric field effect on mixing of gaseous fuel}

Two geometries used in this work as highlighted in the previous chapter are straight and serpentine geometries (Fig. 3 and Fig. 4).

Since this work aims to maintain a laminar flow region, the shape parameters were used to enhance mixing effect, which was helpful for the achieved results. For each of the geometries, five shape parameters were used, inlet velocity of $0.3 \mathrm{~m} / \mathrm{s}$, applied voltage of $50 \mathrm{~V}$, inlet temperature of $500 \mathrm{~K}$, initial concentration of propane gas and oxygen 
were set to $0.15 \mathrm{~mol} / \mathrm{dm}^{3}$ and $0.70 \mathrm{~mol} / \mathrm{dm}^{3}$ respectively. For the straight channel, $\beta$ which is the ratio of the channel width to the channel length was set to be $0.05,0.10,0.15,0.20$, and 0.25 . For the

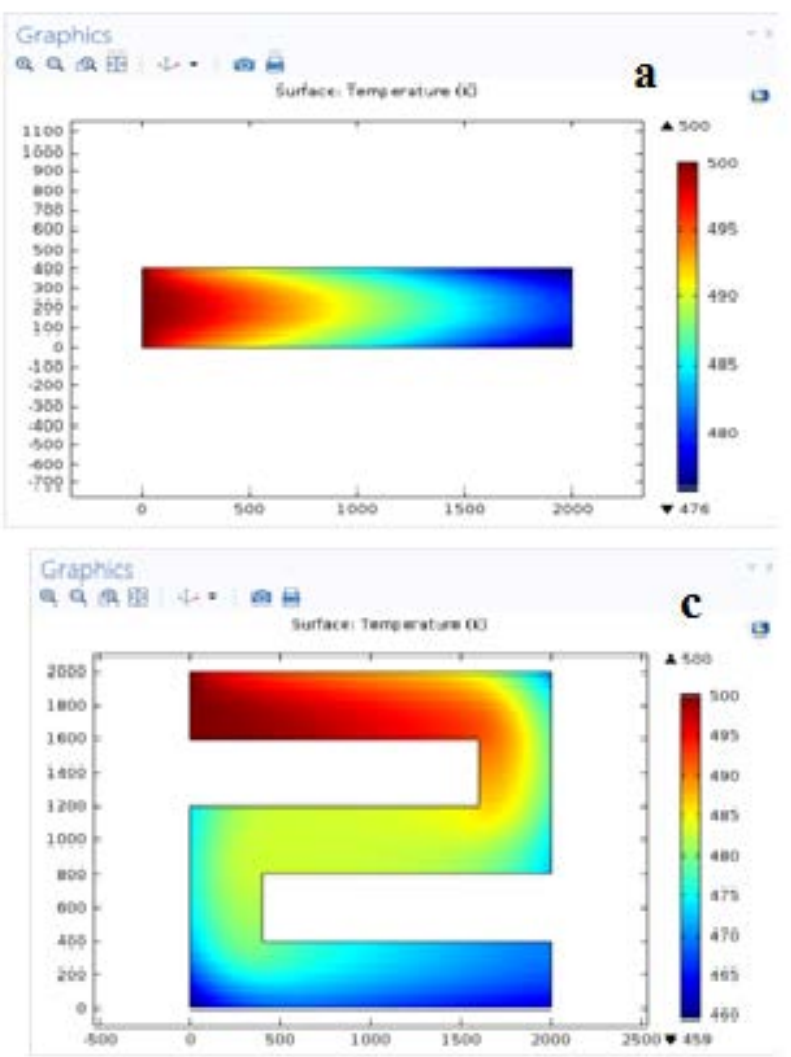

serpentine channel, $\beta$ which is defined as the ratio of bend length to channel length was also set to be 0.05, 0.10, 0.15, 0.20, and 0.25 (See Fig. 5 and Fig. $6)$.

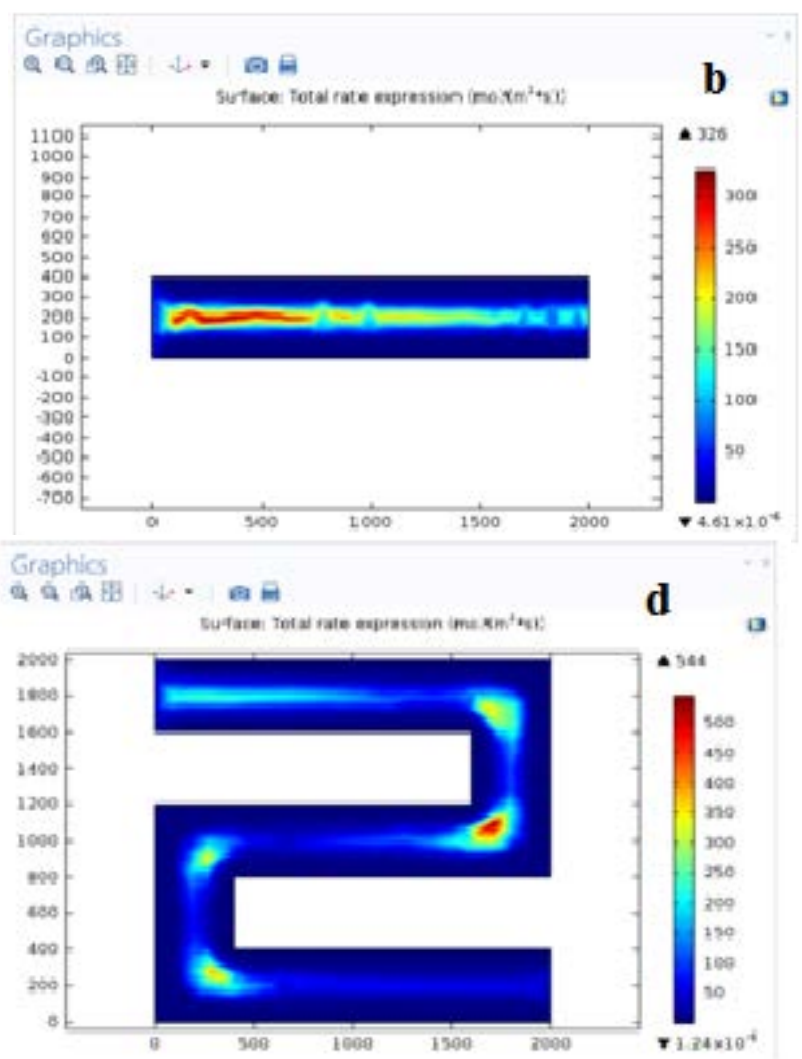

Figure 3. Comparative profiles of temperatures and reaction rate of propane oxidation in straight channel (SC1) and serpentine channel (SC2) micro reactor at (a) Surface temperature SC1; (b)Surface rate of reaction in SC1; (c) Surface temperature in SC2; (d) Surface rate of reaction in SC2

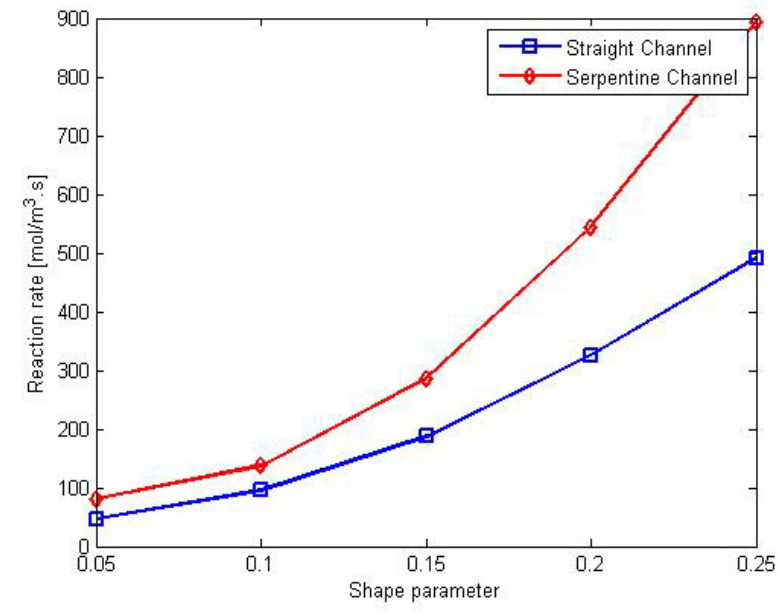

Figure 4. Rate of reaction against shape parameter

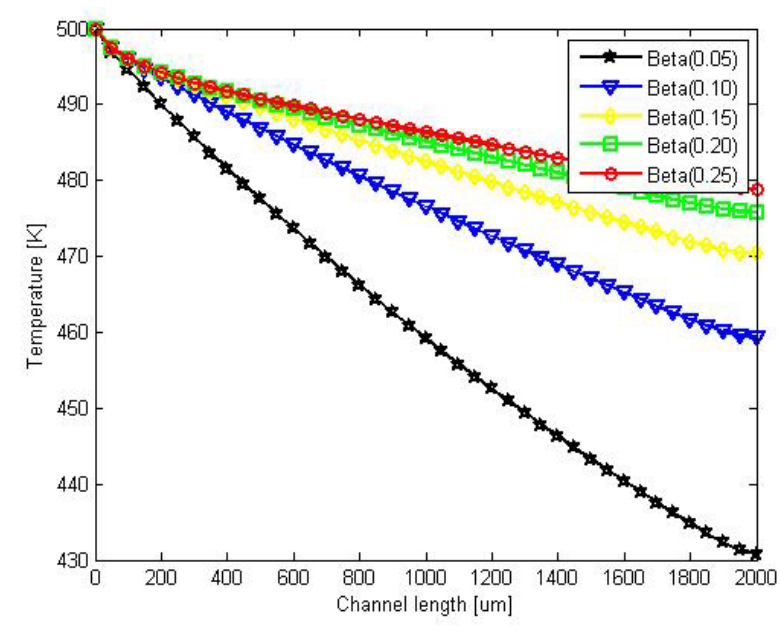

Figure 5. Graph of temperature drop parameters 


\subsection{Effects of the Reynolds number effect on combustion}

The Reynolds number, defined as, $\rho u D_{h} / \mu$ was incorporated in the simulation. Various inlet velocities corresponding to different Reynolds number were used to run a parametric sweep over the straight channel. The result showed that the reaction rate increased with increasing Reynolds number and increasing shape parameter (Fig. 6). This led to a higher propane conversion in the channel. The temperature drop along the channel length was also reduced with increasing Reynolds number for as illustrated in Fig. 7 for $\beta=0.05$, $0.10,0.15,0.200 .25$ for the respective plots in Fig. 8-11.

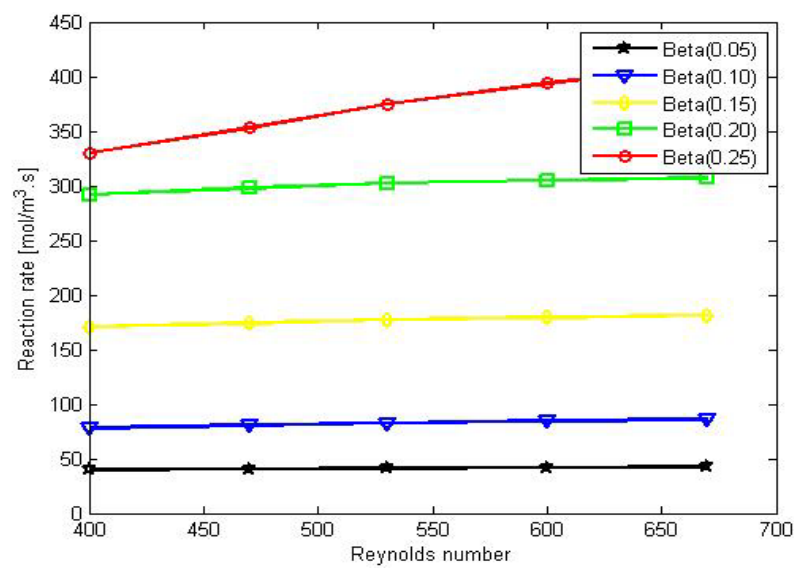

Figure 6. Reaction rate against the Reynolds number

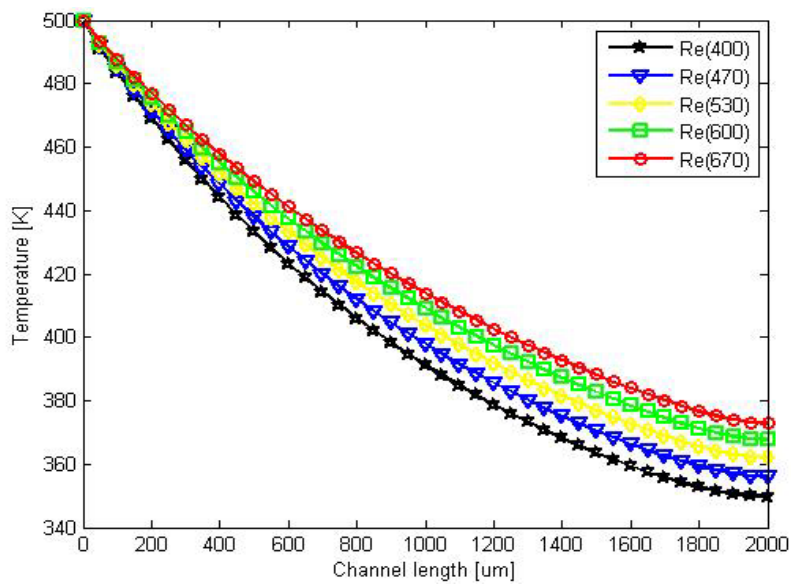

Figure. 7. Temperature drop along the channel length at $\beta=0.05$

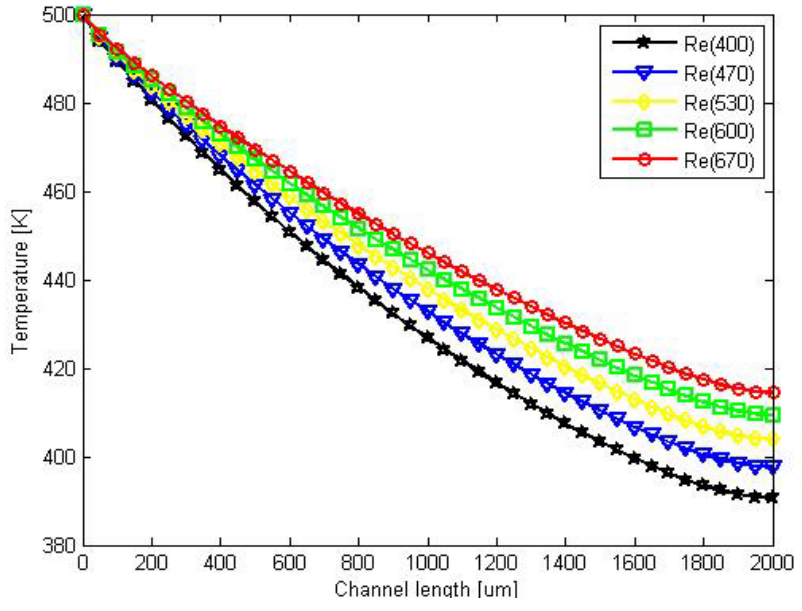

Figure 8. Temperature drop along the channel length at $\beta=0.1$

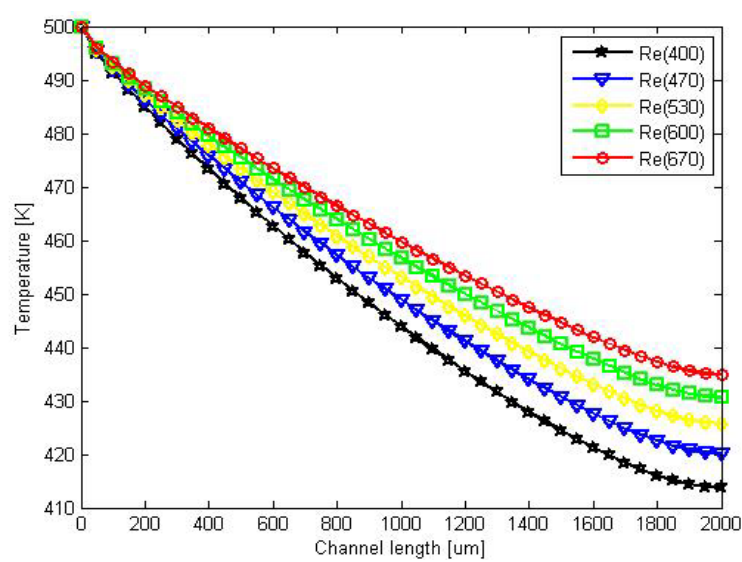

Figure 9. Temperature drop along the channel length at $\beta=0.15$

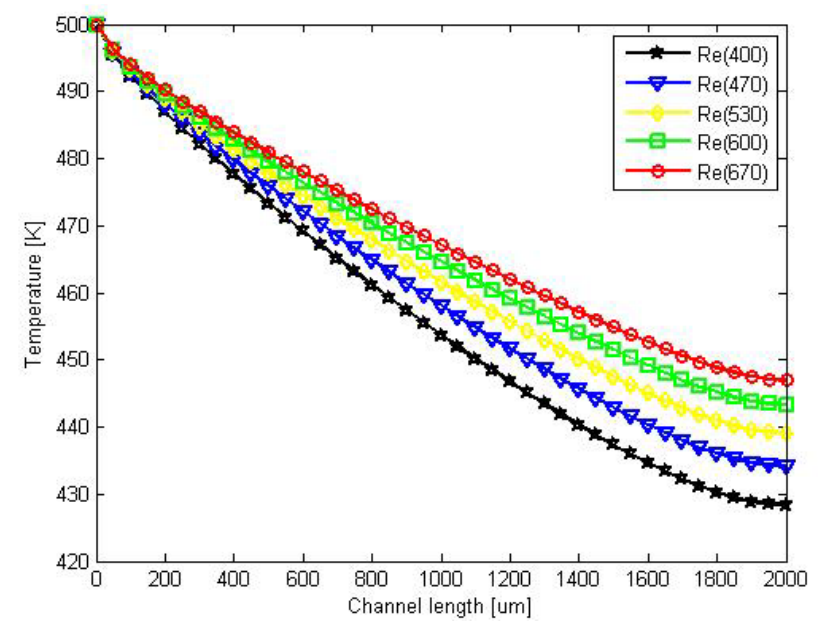

Figure 10. Temperature drop along the channel length at $\beta=0.20$ 


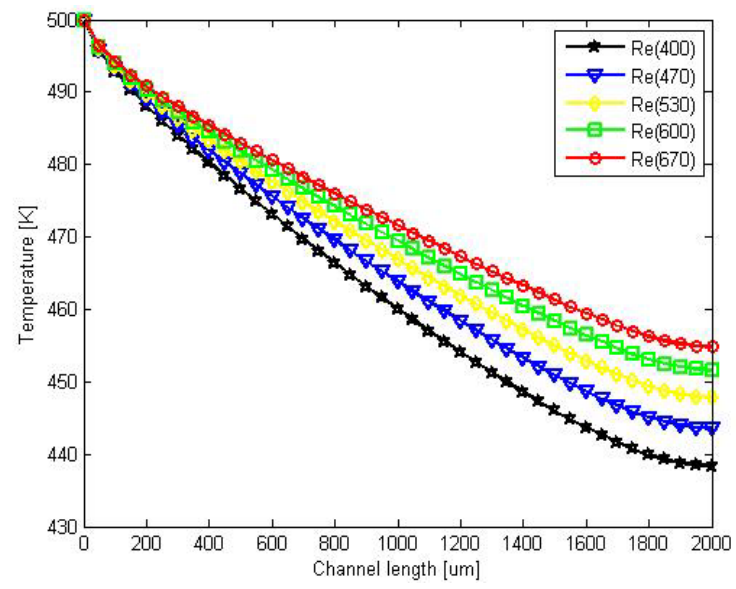

Figure 11. Temperature drop along the channel length at $\beta=0.25$

\subsection{The effect of shape factors on concentration of reactants}

Propane and oxygen concentration drop was studied for $\beta=0.05,0.10,0.15,0.20$ and 0.25 . Figures 12 and 13 respectively show propane and oxygen concentrations at various channel lengths and varying shape factors. Propane concentration reduced from $0.15 \mathrm{~mol} / \mathrm{dm}^{3}$ at inlet to approximately $0.10 \mathrm{~mol} / \mathrm{dm}^{3}$ at outlet for $\beta=0.05$ and to approximately $0 \mathrm{~mol} / \mathrm{dm}^{3}$ at outlet for $\beta=0.25$. Likewise, oxygen concentration dropped from $0.70 \mathrm{~mol} / \mathrm{dm}^{3}$ at inlet to approximately $0.46 \mathrm{~mol} / \mathrm{dm}^{3}$ at outlet for $\beta=0.05$ and to approximately $0 \mathrm{~mol} / \mathrm{dm}^{3}$ at outlet for $\beta=0.25$. It was observed that the concentration drop for both propane and oxygen was proportional to the shape factor $(\beta)$. In other words, an increase in the concentration drop was possible due to an increase in the shape factor.

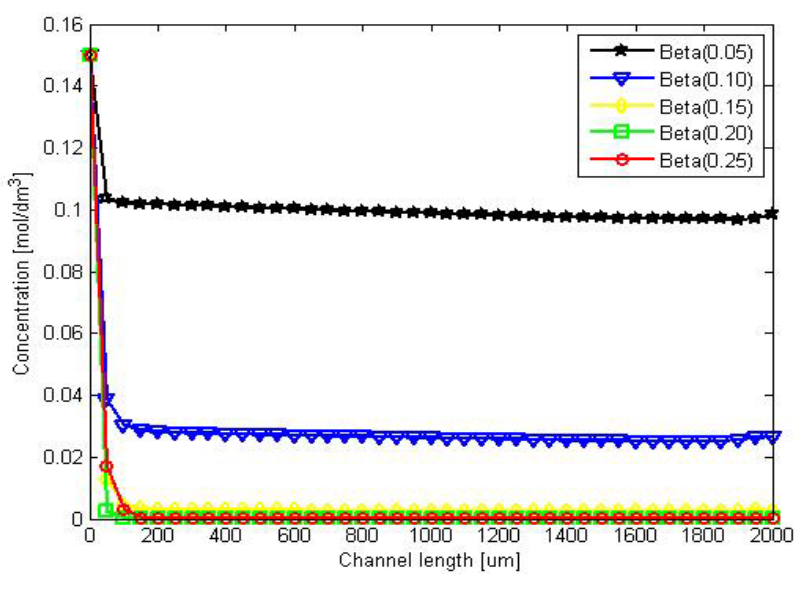

Figure 12. Propane concentration drop along the channel length for different $\beta=0.10$

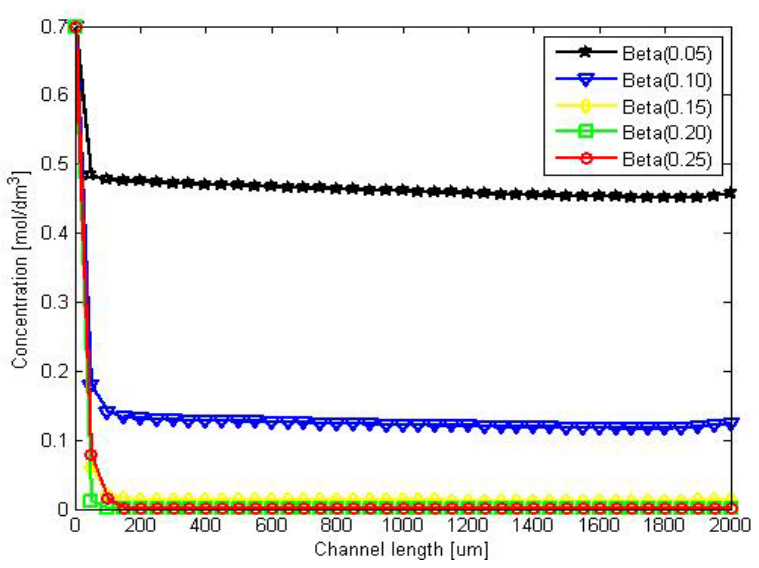

Figure 13. Propane concentration drop along the channel length for different $\beta=0.15$

\subsection{The effect of the Reynolds number on concentration of species}

The Reynolds number effect on the concentration of the reactants (propane and oxygen) was observed in this work. An increase in the Reynolds number led to a decrease in the concentration drop (see Fig. 1415). This was possible because the Reynolds number increases the reaction speed, reduces the reaction time, but unfortunately reduces the concentration of species used up in the reaction. There were no observable changes in the concentration profiles for the respective constructal parameters $\beta=0.10, \beta=0.15, \beta=0.20, \beta=0.25$ 


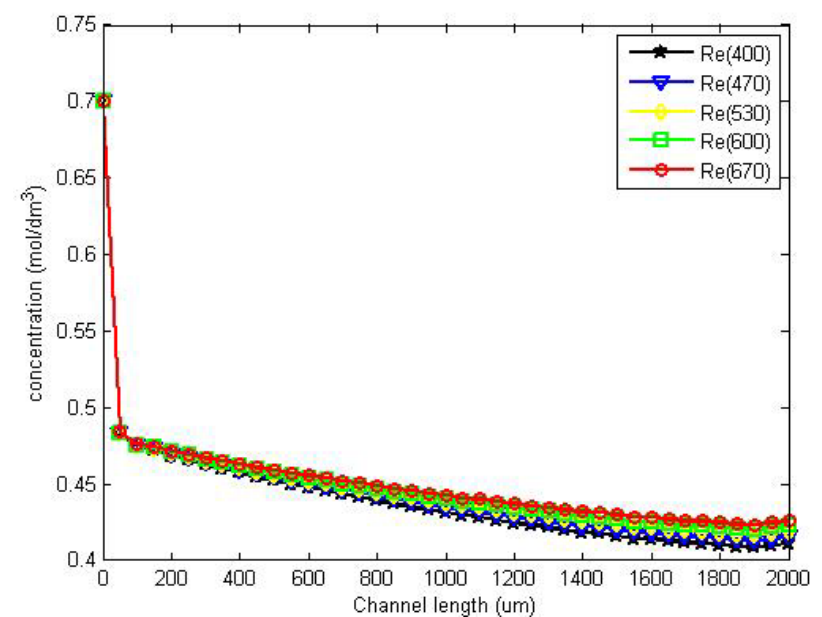

Figure 14. Oxygen concentration drop along the channel length at $\beta=0.05$

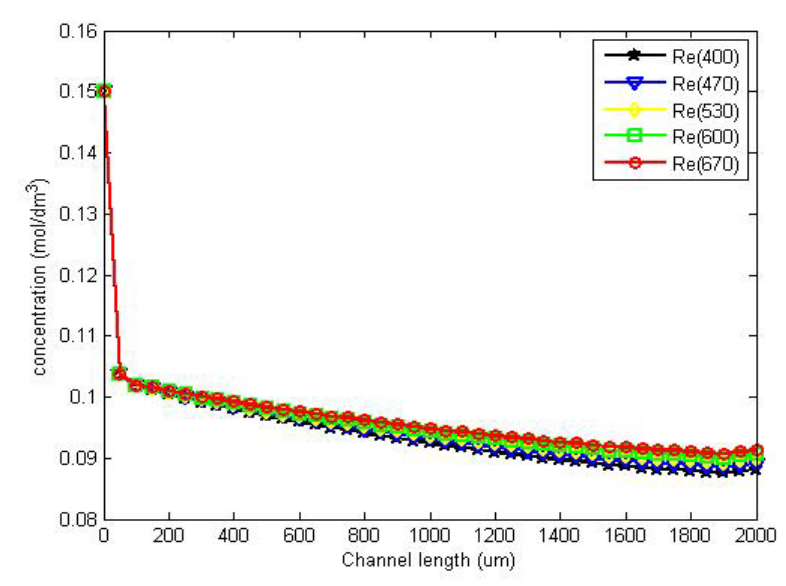

Figure 15. Propane concentration drop along the channel length at $\beta=0.05$

\section{Conclusion}

The limiting issues around the chemical catalytic based enhancement in micro-reactor have been reviewed. Imposition of field catalyzed effect on micro-reactor is presented in this work. Constructal variation of geometric shapes of the microchannel is demonstrated as a determinant to mixing efficiency and reaction stability. Relevant physic-chemical and hydrodynamic equations are computed numerically to determine the distribution of choice parameters such as shape factor, concentration and thermal distribution during the combustion process. The results obtained were properly delineated and showed great improvement in minimising thermal and enhancing auto-ignition propensity in propanefired micro-reactor. Prior to the imposition of electric field, the combustion reaction occurred at elevated temperatures above the propane's auto ignition temperature. The impact of field catalyzed reaction demonstrated at an applied voltage of 50 volts yield combustion of propane fuel at $500 \mathrm{~K}$ below its auto-ignition temperature estimated as 734K [28], [29], [30]. The thermal enhancement is responsible for optimization of the combustion process due to electric field and geometric alterations of the flow confinements. Quantification of clogging incidence, reaction time and the residence time of the reacting species could be conducted to provide time-specific illustration of this procedure. The enhancement of combustion below auto-ignition temperature of fuels could minimize fuel requirement and improve consumption efficiency in miniaturized vehicles. These findings on auto-ignition performance would benefit understanding on multiphase and multi-fuel reaction paradigm for bio-MEMS devices and micro heat engines.

\section{Acknowledgements}

The authors are grateful to the Department of Mechanical Engineering, Faculty of Technology University of Ibadan Nigeria for the support and provision of facilities for this research.

\section{References}

[1] Fu, K., Knobloch, A., Martinez, F. C., Walther, D. C., Fernandez-Pello, C., Pisano, A. P., Liepmann, D.: Design and fabrication of $a$ silicon-based MEMS rotary engine, ASME International Mechanical Engineering Congress and Exposition, New York, 2001.

[2] Palo, D. R., Holladay, J. D., Rozmiarek, R. T., Guzman-Leong, C. E., Wang, Y., Hu, Y., Chin, H., Dagle, R. A., Baker, E. G.: Fuel Processor Development for a Solder-portable Fuel Cell System, Micro Reaction Technology, Proceedings of 5th International Conference on Micro Reaction Technology, (359) 578, 2002.

[3] Sabihuddin, S., Kiprakis, A.E., Mueller, M. A.: Numerical and Graphical Review of Energy Storage Technologies, Energies, 8 (2015), 172216.

[4] Maruta, K., Takeda, K., Sitzki, L., Borer, K., Ronney, P. D., Wussow, S., Deutschmann, O.: Catalytic Combustion in Microchannel for MEMS Power Generation, Proceedings of Third Asia-Pacific Conference on Combustion, Seoul, Korea, June 24-27 2001. 
[5] Kaisare, N. S., Deshmukh, S. R., Vlachos, D. G.: Stability and performance of catalyticmicroreactors: Simulations of propane catalytic combustion on Pt., Chemical Engineering Science, 63 (2008), 1098 - 1116.

[6] Jones, J.: Heat Losses in Conventional- and Insulated Exhaust Ports, Thesis for the Degree of Master of Science, Master of Science Thesis, Department of Energy Sciences Division of Combustion Engines, Lund University, 2015.

[7] Munirathinam, R., Huskes, J., Verboom, W.: Supported Catalysis in Continuous Flow Microreactors, Adv. Synthesis and Catalysis, 357 (2015), 6, 1093-1123.

[8] Dimov, S., Gasenko, O.: Catalytic combustion and steam reforming of hydrocarbons in microreactor, MATEC Web of Conferences 115, 2017.

[9] Men, Y., Kolb, G., Zapf, R., Pennemann, H., Hessel, V.: Total combustion of propane in a catalytic microchannel combustor, Chemical Engineering Research and Design, 87 (2009), 91-96.

[10] Specchia, S., Luigi D. Vella, L. D., Burelli, S., Saracco, G. Specchia, V.: Combustion of $\mathrm{CH}_{4} / \mathrm{H}_{2} /$ air mixtures in catalytic microreactors, Euro. J. Chemphychem, 10:5 (2009), 783-786.

[11] Karagiannidis, S., Mantzaras, J., Boulouchos, K.: Stability of hetero-/homogeneous combustion in propane - and methane fueled catalytic microreactors: Channel confinement and molecular transport effects, Proceedings of the Combustion Institute, 33 (2011), 3241-3249.

[12] McNally, D., Agnello, M., Pastore, B., Applegate, J. R., Westphal, E., Bakrania, S. D.: A Study of Fuel and Reactor Design for Platinum Nanoparticle Catalyzed Microreactors, Journal of Nanomaterials, Article ID:538752, 2015.

[13] Silva, J. E.: Modeling the Chemical, Diffusional, and Thermal Processes of a Microreactor, A Thesis submitted to the Department of Mechanical Engineering in Partial Fulfilments of the Requirements for the Degree of Bachelor of Science in Mechanical Engineering Massachusetts Institute of Technology, 2012.

[14] Chen, J., Xu, D.: Combustion Characteristics and Stability of Methane-Air Mixtures in Catalytic Microreactors, World Journal of Applied Chemistry, 3 (2017), 2, 85-95.
[15] Odesola, I. F., Ashaju, A., Ige, E. O.: Simulation of Flow and Thermal Transport in Gravity-dominated Microchannel, International Journal of Scientific and Engineering Research, 8 (2017), 1, 994-1001.

[16] Ashaju, A., Ige, E. O., Odesola, I. F.: Numerical Modeling of Fluid and Thermal Transport in Gravity-dominated 3D Microchannels, Proceedings of $15^{\text {th }}$ UK Heat Transfer Conference, Burnel University London 4-5 $5^{\text {th }}$ September, 2017.

[17]Dare, A. A., Ofi, O.: The Application of Random Vortex Method in the Analysis of Heat Conduction in a Slab, Proceedings of the 10th WSEAS International Conference on Mathematical and Computational Methods in Science and Engineering (MACMESE'08), 2008, 460-466.

[18]Zuo, W., Jiaqiang, E., Lin, R., Jin, Y., Han, D.: Numerical investigations on different configurations of a four-channel meso-scale planar combustor fuelled by hydrogen/air mixture, Energy Conversion and Management, 160 (2018), 1-13.

[19] Peng, Q., Jiaqiang, E., Chen, J., Zuo, W., Zhao, $\mathrm{X}$., Zhang, Z.: Investigations on effects of wall thickness and porous media on the thermal performance of a non-premixed hydrogen fuelled cylindrical micro combustor, Energy Conversion and Management, 155 (2018), 276286.

[20]Peng, Q., Jiaqiang, E., Zhang, Z., Hu, W., Zhao, $\mathrm{X}$.: Investigation on the effects of front-cavity on flame location and thermal performance of a cylindrical micro combustor, Applied Thermal Engineering 130 (2018), 541-551.

[21] Jiaqiang, E., Zuo, W., Liu, X., Peng, Q., Deng, Y., Zhu, H.: Effects of inlet pressure on wall temperature and exergy efficiency of the microcylindrical combustor with a step, Applied Energy, 175 (2016), 337-345.

[22] Némethné-Sóvágó, J., Benke, M.: Microreactors: A New Concept For Chemical Synthesis and Technological Feasibility, Materials Science and Engineering, 39 (2014), 2, 89-101.

[23] Moorman, M., Manginel, R. P., Colburn, C. W., Mowery-Evans, D. L., Clem, P. G., Bell, N. S., Anderson, L. F.: Microcombustion array and micro-flame Ionization Detector for Hydrocarbon Detection, In Proceedings of MEMS Components and Applications for Industry, Automobile Aerospace and 
Communication II, Volume 4981, San Jose, CA United States, 2003.

[24] Kohnle, J., Waibel, G., Cernosa, R., Storz, M., Ernst, H., Sandmaier, H., Strobelt, T., Zengerle, R.: A unique solution for preventing clogging of flow channels by gas bubbles, Proceedings of IEEE International Conference on Micro Electro Mechanical Systems- MEMS 2002, Las Vegas, NV, USA, 77-80.

[25] Pr ‘byl, M., Šnita, D., Marek, M.: Nonlinear phenomena and qualitative evaluation of risk of clogging in a capillary microreactor under imposed electric field, Chemical Engineering Journal,Volume 105, Issue 3, 15 January 2005, 99-109.

[26] Schoenitz, M., Grundemann, L., Augustin, W., Scholl, S.: Fouling in microstructured devices: a review, Chem. Commun., 51 (2015), 82138228.
[27] Rubesa, A., Travas, C.: A Physcial Model of Convective-Dispersive Transport in an Intergranular Porous Material, Engineering Review, 33 (2013), 141-150.

[28] Cadman, P., Thomas, G.O., Butler, P.: The Auto-ignition of Propane at intermediate Temperatures and High Pressure, Physical Chemistry Chemical Physics, 23 (2000), 54115419.

[29] Agafonov, G.L., Tereza, A.M.: Autoignition of Propane behind Shock waves, Russian Journal of Physical Chemistry B, 9 (2015), 1, 92-103.

[30] Morganti, K.J., Brear, M. J.: The Autoignition of Liquefied Petroleum Gas (LPG) in Sparkignition Engines, Proceedings of Combustion Institute, 35 (2015), 3, 2933-2940. 